\title{
A computer-driven undergraduate laboratory curriculum and related support logistics
}

\author{
CHARLES R. LEITH, HARLYN D. HAMM, CONNIE DUNCANSON, and TANJA SENICAL \\ Northern Michigan University, Marquette, Michigan
}

\begin{abstract}
A psychology department in a teaching university solved problems in the existing undergraduate laboratory courses by setting up a computer laboratory and developing its own software. The logistical support that allowed a small department to offer many laboratory experiences came in part from an undergraduate apprenticeship program, which is described.
\end{abstract}

It seems appropriate to begin this case history of the use of microcomputers in the classroom with a brief description of our institution. Northern Michigan University serves 6,900 students with 28 academic departments. The Department of Psychology has 8.3 faculty and 125 undergraduate majors. Because we serve several other majors and have a few large lecture courses, the credit hour production per faculty is among the highest of all departments on campus. The Department of Psychology has a long history of offering laboratory experiences. About half of our current offerings have laboratories attached. Weekly scheduled laboratories with 30 students per section are offered in introductory psychology ( $15 \mathrm{sec}-$ tions per year), learning ( 2 sections per year), physiological psychology ( 2 sections per year), and social psychology (2 sections per year). Research projects are assigned in advanced physiology, advanced learning, cognition, sensation, and animal behavior, each of which serves about 10 students a year. In total, we offer lab experiences to about 680 students a year. Obviously, we have a support system, described below, that makes it possible to offer so many labor-intensive laboratories with so few faculty. Note that we were converting an already functioning laboratory system to the use of computers. This makes our experience somewhat different from that of a department starting a new laboratory system that uses computers.

\section{A FEW PROBLEMS}

Until this year traditional human or animal (rat) experiments had been the core of our laboratory offerings. These had several limitations: Some demonstrations of great educational merit simply cannot be performed, out of ethical concern for the subjects of the experiments; human subjects sometimes failed to keep appointments; rats escaped, got sick, bit students, and (perhaps the final straw) caused strong allergic reactions in several of the faculty, including the department head; the large rat colony was

Requests for reprints should be sent to Charles $R$. Leith, Department of Psychology, Northern Michigan University, Marquette, MI 49855. expensive to maintain and was not large enough to service all of the introductory psychology laboratories.

\section{A PROPOSED SOLUTION}

The members of our department were open to a technical solution to these problems. The Department of Psychology had been among the first on campus to computerize its office, we had computer control apparatus in our research labs, and we had tried an early set of classroom computer programs written by Perera (1981) for the inadequate TRS-80 Model 1 . In 1985 it occurred to us that we could use computer simulations to replace the rats in our introductory psychology sections and use computers to provide apparatus in the laboratory sections of other classes. In our innocence and ignorance we even thought this to be an original idea.

\section{A TRIAL RUN WITH COMMERCIAL SOFTWARE}

The representatives of the commercial text publishers were quick to inform us that software for undergraduate psychology laboratories was available or in development. We decided to try a test run of one computer-based section of introductory psychology, using the campus MSDOS facility (60+ monochromatic PCs in a large room). We bought an attractive-looking package by Hay (1985) called PsychWorld and used it in the winter semester of 1986. Students responding to an evaluation questionnaire said that the computer programs helped them to understand many concepts in psychology, but relatively few said that the laboratory taught them science. (In contrast, the students in the regular animal laboratory class said they had learned about science in the laboratory but did not learn many psychological concepts.) The faculty's evaluation of the laboratory was that PsychWorld would not be an effective substitute for our standard practice. In order to fit into our curriculum, a computer laboratory would have to fill a 100-min scheduled laboratory period and occupy the hands and minds of the three-person research team at each work station. The PsychWorld soft- 
ware was really intended to provide 50-min tutorials for one operator at a time. Rather than look for a more appropriate set of programs, we assumed (naively and perhaps unfairly) that our needs would be too special for the commercial developers and decided to write our own.

\section{PLANNING OUR OWN SOFTWARE}

Over the next few months we tried out some basic programming ideas on both an MS-DOS and a Commodore 64 computer that happened to be available in the department. We gradually formulated a set of objectives that could be described as follows:

1. We wished to create a complex, fascinating, colorful, alternate reality. The freshman users were, after all, veterans of the video arcades. A simulated piece of equipment should have buttons to be pushed, knobs to be turned, meters to be read, digital counters to be recorded and reset, lights to be flashed. A simulated rat should be a veritable Rat Headroom.

2. We wished to keep everyone busy. Each member of our standard three-student teams should have some role to play in the operation of the laboratory simulation. The students should choose the stimuli, pace the trials, record the data, and control events. The students should never have to sit and passively watch the computer act out roles.

3 . We wished to have a variety of programs that would help students in almost any course offered by the department. We wanted to build a library of experiments, demonstrations, and interactive tutorial animated displays that could serve all courses, not just laboratory courses.

In retrospect, this approach appears to have converged with some of the ideas put forth by scholars in the field. In order to meet the first two objectives we had to write programs with "depth." Such programs have qualities that allow what Castellan (1984) described as "vertical integration." For example, in our Intelligent Rat program, a cartoon rat moves about in a fairly complex (and experimentally manipulable) environment and learns from experience, displaying what Steinhauer (1986) called "artificial behavior." This program is used to show introductory psychology students how to shape behavior, while advanced learning students must deduce from a series of careful experiments which theory is controlling the rat's behavior. Our third objective resulted in programs and program usage that most nearly resemble the electronic chalkboard function described by Spivey and Jackson-Smith (1984).

\section{CHOOSING THE HARDWARE}

In mid-1986 we had to commit ourselves to hardware. In view of our low budget, our minimal BASIC programming skills, and our glorious video-arcade ambitions, the Commodore $\mathrm{C}-128$ appeared to be our best bet. This machine has a powerful sprite graphics system and a BASIC 7.0 language that makes using the graphics easy (no PEEKS or POKES). In addition, the naive user can load and run a program on the C-128 by merely turning on the power switch. The laboratory facility as presently set up contains 10 student work stations and 1 instructor work station that displays (very effectively) through a 44-in. rear-projection television set. Our hardware could be duplicated for a little over $\$ 9,000$.

\section{WRITING AND USING OUR OWN SOFTWARE}

One of us using one-third released time in the spring term 1987 and two of us working virtually full-time in the summer were able to create enough software to run the fall 1987 introductory psychology laboratories in the new 10 -station computer room. Although it is too soon to provide a definitive evaluation of the software, a sample of student opinion shows that they felt the laboratory helped them to understand many concepts in psychology and to learn about science. As programmers, we found a few details that needed improving, but none of the programs demonstrated fatal flaws. A program is no better than the lesson plan and laboratory manual that call for its use. Since not enough time was allowed for writing the laboratory manuals, we ran a few pages ahead of the students in the last half of the semester.

\section{MOVING TOWARD A COMPUTER-DRIVEN CURRICULUM}

We now take 270 introductory psychology students per semester through the laboratory experience, and we plan to expand this to 400 per semester. Use of the new computer room is reaching its limits, and this will get worse as the library of programs grows. The department is already installing an additional five-station computer room to handle the needs of the advanced courses. Eventually every laboratory-oriented course will use simulations (instead of animals) to show rare, dangerous, expensive, or ethically unrepeatable experimental conditions.

The most interesting use we have made of our computers is in a course in which advanced students write programs that simulate some classic experiment or important psychological phenomenon. The students are required to select a topic reflecting their own interests or those of the instructors, make a set of graphics that illustrate or simulate the phenomenon, and then write a program that sets the display/simulation in motion. These students must come to really understand a psychological phenomenon and a computer program in order to complete the task. The knowledge that their programs, if high enough in quality, may be used to teach future generations of students is a powerful incentive to this group.

\section{LOGISTICAL SUPPORT FOR THE UNDERGRADUATE LABORATORY}

The development of our computer laboratory would have been impossible had it not been for the existing 
laboratory support structure. Laboratory courses do require space and equipment, but the most difficult problem is that they consume time and effort far faster than do lecture courses. Someone must be present to explain the experimental task, answer students' questions, help students use the apparatus, prevent students from making mistakes that are expensive to undo, prevent vandalism, and collect students' laboratory reports. Later someone must read the laboratory reports, offer constructive criticism, grade them, and record the grades. These responsibilities require judgment and knowledge of the laboratory, but do not require a $\mathrm{PhD}$. In research universities these tasks are frequently assigned to graduate students as a form of onthe-job training.

\section{Apprentices}

We do not have graduate students at Northern Michigan University, but we do have students bound for graduate school who will clearly benefit from any experience that will make the first years of graduate school less strange and threatening. In this context we have offered (since 1969) a special 1- or 2-h course called "Professional Activities in Psychology," which allows students to serve under supervision as apprentice research assistants or teaching assistants.

Students are not permitted to accumulate more than 6 semester hours of credit in apprenticeship, so that it cannot be used to evade content courses. Students may take the apprenticeship for a grade if they pay tuition, or merely for advancement toward graduation if they do not pay tuition. This option has enabled many financially pressed students to participate in this unrequired activity. In special cases students may repeat an apprenticeship with more duties, including supervision of new apprentices. These more responsible apprenticeships are officially recognized as "Advanced Professional Activities." Each apprentice must agree with his/her sponsor to a behavioral contract clearly describing the proposed apprenticeship, and this agreement must be approved by the department head. This rule was intended to prevent students from being exploited, and to provide a general review of the program.

\section{Faculty Responsibilities Toward Apprentices}

The faculty who recruit and accept apprentices have a special responsibility to choose competent students who will be successful apprentices. For the most part, teaching apprentices are recruited from among the top previous students in the class for which they are to serve as apprentices. Even a shy person finds it easy to assume the role of leader when he/she is the only one in the room who knows from experience what is supposed to happen next. When sensitive activities such as grading are required of an apprentice, the faculty responsible must supervise the apprentice very closely.

\section{Apprentices in the Laboratories}

Our introductory psychology computer laboratory has carried over the staffing plan of the old animal laborato- ries. In each section of the course, an apprentice guides the students through the procedures, answers questions, and checks written reports. To monitor the apprentices, we hire teaching assistants (frequently former apprentices) who supervise two sections each. The apprentices and the teaching assistants are supervised by the faculty member who is assigned to teach the course. Of course, the organization of the assistants and apprentices can be modified to suit the style of the instructor. The computer-based experiments appear to be less demanding of assistants' and apprentices' time and skill than the old animal experiments; however, we may decide not to reduce the number of apprentices, since reducing opportunities for apprenticeships could be a counterproductive economy in our program.

\section{Some Indicators of Success}

Since 1969 Northern Michigan University has given 1,000 semester credit hours for teaching apprenticeships and only a few hundred less for research apprenticeships. Apprentices have appeared about 324 times as coauthors on professional papers or publications, including this one. Our graduate-school-bound students have had a very high acceptance rate, and they feel very well prepared when they enter the graduate-school environment. The apprenticeship program has made it possible for a small psychology department to offer an especially rich set of experiences, including the computer-based laboratory.

\section{CONCLUSION}

The cost of the basic 10-station laboratory facility will be repaid in 3 to 5 years by savings from the closing of the rat colony. (A smaller animal colony continues to serve the research needs of the department.) The reduction in allergic reactions in the laboratory wing of our building is a considerable benefit. Both our teaching apprentices in the computer laboratories and the students who write educational software for the computers will have unusual and impressive credentials on their vitae when they graduate. Preliminary student evaluation data suggest that the computer laboratory will be a more effective learning environment than the old animal laboratory. In short, we feel confident that the shift to computer laboratories has been a change for the good.

\section{REFERENCES}

Castellan, N. J. (1984). A model for courseware development in psychology. Behavior Research Methods, Instruments, \& Computers, 16, 165-167.

Hay, J. C. (1985). PsychWorld [Computer Program]. New York: McGraw-Hill.

Perera, T. B. (1981). A laboratory in experimental psychology using the TRS-80. Behavior Research Methods \& Instrumentation, 13, 195-197.

SPIVEY, J., \& Jackson-Smith, P. (1984). The electronic chalkboard. Behavior Research Methods, Instruments, \& Computers, 16, 172-175.

Steinhauer, G. D. (1986). Artificial behavior: Computer simulation of psychological proceses. Englewood Cliffs, NJ: Prentice-Hall. 